\section{Anaphylaxis Due to Poloxamer 238}

Carbonell $\mathrm{A}^{1}$, Escudero AI ${ }^{1}$, Miralles $\mathrm{JC}^{1}$, González $\mathrm{A}^{1}$, Navarro $\mathrm{C}^{1}$, Cardona $\mathrm{P}^{1}$, Jimeno $\mathrm{L}^{2}$, Pineda $\mathrm{F}^{3}$

${ }^{1}$ Allergy Section, Hospital General Universitario Reina Sofía, Murcia, Spain

${ }^{2}$ ALK-Abelló Laboratories, Madrid, Spain

${ }^{3}$ Diater S.A. Laboratories, Madrid, Spain

J Investig Allergol Clin Immunol 2018; Vol. 28(6): 419-420 doi: 10.18176/jiaci.0298

Key words: Poloxamer 238. Poloxamer-induced reactions. Complement activation. IgE-mediated hypersensitivity.

Palabras clave: Poloxamer 238. Reacciones inducidas por Poloxamer. Activación del Complemento. Hipersensibilidad mediada por lgE.

We present a clinical case of anaphylaxis due to poloxamer 238. Poloxamers are recognized pharmaceutical excipients that can be used in micellar form to increase both the solubility and the stability of drugs. In addition to their use in drug delivery, poloxamers have also been reported to sensitize drug-resistant cancers to some antineoplastic drugs, thus increasing transport of the drugs across the blood-brain barrier and enhancing oral bioavailability [1].

The patient was a 59-year-old woman, with a history of bronchial allergic asthma and sensitization to olive and Parietaria pollen.

In November 2016, she was diagnosed with breast cancer. During the radiological examination to detect a sentinel lymph node, a marker with Tc99m (Nanocoll) was administered intravenously. In less than 15 minutes, the patient began to experience itching and intense erythema in the groins, neck, mouth, and lips, followed by swelling of the tongue, dizziness, sweating, and intense dyspnea. She needed emergency care, which took the form of epinephrine, dexchlorpheniramine, and methylprednisolone. The patient was then transferred to hospital, where she recovered after hours of treatment and observation in the emergency department.

Intravenous Nanocoll is a radiopharmaceutical containing Tc99m in the form of sodium pertechnetate with nanocolloid human serum albumin and poloxamer 238. The other excipients are anhydrous glucose, stannous chloride dihydrate, sodium phosphate, anhydrous sodium phytate, and nitrogen.

The results of skin prick testing and intradermal testing with human albumin were negative. Skin prick testing and intradermal testing (1:1000) with poloxamer 238 were positive (Figure).

The results of prick and intradermal testing with poloxamer 238 were also negative in 5 controls.

We then performed dot-blot IgE-immunodetection, which yielded negative results. No specific IgE binding to the material analyzed was detected [2], although specific IgE to other pharmaceutical excipients has been reported using this technique [3].

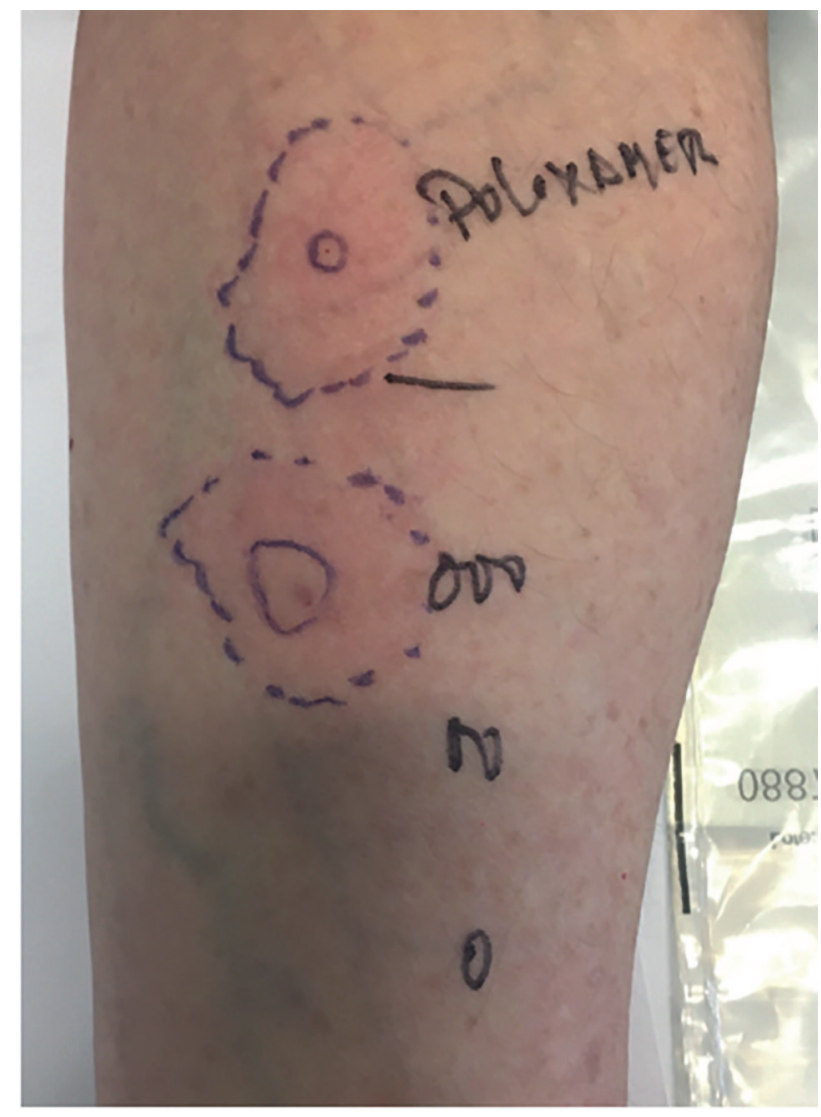

Figure. Positive skin prick test and intradermal test (1:100) with poloxamer 238.

A subsequent histamine release test showed that $22 \mathrm{ng} / \mathrm{mL}$ of histamine was released when poloxamer 238 was added to the patient's basophils, in comparison with $14 \mathrm{ng} / \mathrm{mL}$, when we simply added the buffer that accompanies the technique (negative control). Therefore, the release of histamine generated with the drug that caused the symptoms exceeded the positivity cut-off of the technique $(15 \mathrm{ng} / \mathrm{mL})$, and the result of the test was considered positive. $7 \% \mathrm{HClO}_{4}$ was used as positive control [4-6].

Adverse non-IgE-mediated hypersensitivity reactions have been described following intravenous injection of poloxamer 188-based pharmaceuticals, presumably via complement activation [7].

To our knowledge, we present the first case of anaphylaxis due to poloxamer 238 administered with a radiopharmaceutical causing clinical symptoms and in which histamine release was demonstrated.

We were unable to demonstrate specific IgE binding using the dot-blot technique, although the positivity of the skin test suggests that an IgE-mediated mechanism could be involved.

\section{Funding}

The authors declare that no funding was received for the present study. 


\section{Conflicts of Interest}

The authors declare that they have no conflicts of interest.

\section{References}

1. Kabanov AV, Alakhov VY. Pluronic block copolymers in drug delivery: From micellar nanocontainers to biological response modifiers. Crit Rev Ther Drug Carrier Syst. 2002;19:1-72.

2. Sánchez-Madrid F, Morago G, Corbi AL, Carreira J. Monoclonal antibodies to three distinct epitopes on human IgE: their use for determination of allergen-specific IgE. J Immunol Methods. 1984;73:367-78.

3. Caballero ML, Lluch-Bernal $M$, Vilà-Nadal $G$, Lluncor $M$, Quirce S. IgE-Mediated Anaphylaxis Induced by Macrogol 6000. J Investig Allergol Clin Immunol. 2016; 26:398-400.

4. Arribas F, Falkencrone S, Sola J, Gomez-Serranillos MP, Laguna JJ, Montañez MI, et al. Basophil Histamine Release Induced by Amoxicilloyl-poly-L-lysine Compared With Amoxicillin in Patients With IgE-Mediated Allergic Reactions to Amoxicillin. J Investig Allergol Clin Immunol. 2017;27:356-62.

5. Pineda F, Ariza A, Mayorga C, Arribas F, González-Mendiola $\mathrm{R}$, Blanca-López $\mathrm{N}$, et al. Role of Histamine Release Test for the Evaluation of Patients with Immediate Hypersensitivity. Reactions to Clavulanic Acid. Int Arch Allergy Immunol. 2015;168:233-40.

6. Harada N, Hiragun M, Mizuno M, Kawaguchi T, Ishii K, Yanase $Y$, et al. A Case of Erythritol Allergy Studied by Basophil Histamine Release and CD203c Expression In Vitro in Addition to a Challenge Test In Vivo. J Investig Allergol Clin Immunol. 2016;26:135-6.

7. Moghimi SM, Hunter AC, Dadswell CM, Savay S, Alving CR, Szebeni J. Causative factors behind poloxamer 188 [Pluronic F68, Flocor]-induced complement activation in human sera. A protective role against poloxamer-mediated complement activation by elevated serum lipoprotein levels. Biochim Biophys Acta. 2004;1689:103-13.

Manuscript received May 15, 2018; accepted for publication July 25, 2018.

Ana Isabel Escudero Pastor

Puerta Nueva, 8, 5th B 30001 Murcia

Spain

E-mail: anaiescuderop@gmail.com 